\title{
Small Molecule Inhibitors of the Prolactin Receptor in Breast Cancer
}

\author{
Eric M. Jacobson ${ }^{1}$, Ruben Papoian ${ }^{2}$ and Nira Ben-Jonathan*,3 \\ ${ }^{1}$ Division of Endocrinology, Department of Internal Medicine; ${ }^{2}$ Drug Discovery Center and ${ }^{3}$ Department of Cancer and \\ Cell Biology, University of Cincinnati College of Medicine. Cincinnati, OH 45267, USA
}

\begin{abstract}
Breast cancer is both a common and a significant health concern for women across the globe. Emerging evidence suggests that the prolactin (PRL) signaling cascade contributes to the pathophysiology of breast cancer as well as to chemoresistance. The importance of this pathway to breast cancer has been elucidated by in vitro studies, genetic manipulations in mice, and case control analyses in human populations. To date, a number of different strategies, none of which have yet made it to the clinical stage, have been advanced as a means for blocking the PRL receptor (PRLR). This paper presents the rationale and strategy for the development of novel small molecule competitive antagonists of the PRLR as a therapeutics in breast cancer. It is predicted that the future of breast cancer treatment will continue to evolve and will be different than what it is today. Combination therapies will be applied that will concurrently target multiple molecules of interest. Novel small molecules will be employed as a means to turn off the PRL signaling pathway in breast cancer cells. Different molecules may well be applied to different genotypic individuals on the basis of the polymorphism profile that their PRLR harbors.
\end{abstract}

Keywords: High throughput screening, prolactin receptor, breast cancer, small molecule inhibitors.

\section{INTRODUCTION}

Each year, over a million women worldwide are diagnosed with breast cancer, accounting for $25 \%$ of all female cancers. About 1 in 8 women are predicted to develop this disease during her lifetime [1]. Over the last two decades, single and combination chemotherapy, based on results from clinical trials, has led to a considerable reduction in morbidity and increased survival of breast cancer patients. However, a standstill was eventually reached, where treatment selection could not be further improved. The logical solution was to find biomarkers that would predict the response to a particular therapy. This approach has been well validated with respect to several tumor-related biomarkers. One of the best examples is the expression of estrogen receptors (ER) in a large percentage of breast tumors, many of which remain sensitive to the mitogenic activity of estrogens. To prevent stimulation of ER-positive tumors by estrogens, two approaches have been employed. One is to block the ER by drugs such as tamoxifen and raloxifene which are members of the growing class of Selective Estrogen Receptor Modulators (SERMs) [2]. Another approach is to prevent the conversion of steroid precursors to estrogen by drug such as anastrazole and letrozole, which belong to the family of aromatase inhibitor [3].

Genetic profiling has also been successful in identifying breast cancer patients with amplification of the HER-2 gene, whose tumors can carry as many as 50 to 100 copies instead of the usual 2 copies per cell [4]. HER-2 positive patients respond well to the humanized monoclonal antibody

*Address correspondence to this author at the Department of Cancer and Cell Biology, University of Cincinnati College of Medicine, Cincinnati, OH 45267, USA; Tel: 513-558-4821; Fax: 513-558-4823;

E-mail: Nira.Ben-Jonathan@uc.edu trastuzumab. Personalized medicine has also been applied to patients with TOP $2 A$ aberrations, who respond better to anthracyclines than those with normal TOP2A gene [5]. In addition, variants of the genes $B R C A 1$ and $B R C A 2$, found in a small percentage of the population, can identify susceptible individuals in families with a history of breast cancer [6]. The next step/phase in the advancement of breast cancer therapy is the identification of new molecular targets followed by the design of appropriate modalities directed against these targets. Small molecules, which are specific against strategic cellular targets, will likely spearhead this advancement. As such, the focus of this review is on the development of small molecule therapeutics against as yet an unexploited target, the PRLR.

\section{PROLACTIN AND ITS ROLE IN BREAST CANCER}

PRL is a $25 \mathrm{kDa}$ hormone produced by the anterior pituitary whose main target is the breast, where it stimulates lobulo-alveolar growth, differentiation and pro-survival [7]. PRL is a pleiotropic hormone whose biological effects extend to the support of lactation, control of steroidogenesis, maternal behavior, osmoregulation, and effects on metabolism and the immune system. In humans, PRL is also produced in many extrapituitary sites, including the breast, where it acts as an autocrine/paracrine factor [8]. PRL belongs to a family of proteins, the lactogens, which share structural homology and some overlapping functions. The three most prominent members are hPRL, growth hormone (hGH) and placental lactogen (hPL) which diverged from a common ancestral gene [9]. They share a tertiary structure made of four anti-parallel, up-up, downdown helical bundle, but have a limited primary sequence homology except for an identical location of the disulfide bridges [10]. Despite their structural differences, each of the lactogens is capable of binding to the human PRLR and triggering its signaling cascade [11]. 
PRL is associated with a higher risk of developing breast cancer and enhancement of tumor growth and metastasis, as revealed by epidemiological studies that higher serum PRL levels in premenapusal women are associated with increased risk of breast cancer [12]. This association is strengthened by many in vitro studies showing that PRL stimulates breast cancer cell (BCC) proliferation and survival [13]. Furthermore, an ectopic production of PRL by BCC stimulates their proliferation in an autocrine manner [14]. The fact that PRL reaches the breast not only from the pituitary via the blood but also from local sources has often been often overlooked. Using RT-PCR, metabolic labeling and a sensitive bioassay, our laboratory reported a 10-15 fold higher PRL production in breast adipose tissue than the adjacent epithelium [15]. Other studies have shown that the majority of breast carcinomas stained positive for PRL [16].

Animal models have reinforced the strong association between PRL and mammary tumorigenesis. For example, mitogenic and anti-apoptotic properties of local PRL were confirmed by finding a faster growth of tumors derived from PRL-overexpressing BCC in nude mice, which was accompanied by increased expression of both the PRLR and the anti-apoptotic protein Bcl-2 in the tumors [14]. Over $70 \%$ of transgenic mice with PRL over-expression in their mammary epithelium developed mammary carcinomas, characterized by intraepithelial neoplasias and invasive neoplasms [17]. Treatment with PRL increases the development of de novo tumors in normal mice, and PRL interacts with chemical carcinogens in the induction of mammary tumors [18].

\section{PRL AS A CHEMORESISTANCE AGENT}

Exploration of the mechanism by which PRL antagonizes anticancer drugs was inspired by our previous finding that PRL overexpression in MDA-MB-435 BCC enhanced tumor growth and upregulated Bcl-2 [14]. Subsequently we found that pretreatment of $\mathrm{BCC}$ with low doses of PRL antagonizes cytotoxicity by taxol, vinblastine, doxorubicin and cisplatin, albeit at different efficacies [19]. We were especially interested in the mechanism by which PRL opposes cisplatin which shows only little effectiveness in breast cancer patients. Unlike its strong apoptotic effects in MDA-MB-468 cells, cisplatin was only moderately effective in T47D cells. Reasoning that the resistance of T47D cells may be due to high endogenous PRL levels, the mechanistic studies were conducted with MDA-MB-468 cells.

Measurement of platinum in nuclear extract by mass spectroscopy reveals that PRL reduces the amount of cisplatin bound to DNA. The lower entry of cisplatin into the nucleus could be due to transporters such as multi-drug resistance proteins (MRP) that extrude drugs, or to detoxification enzymes such as glutathione-S-transferase (GST) that inactivate cisplatin [20]. Using inhibitors of the two potential targets, we discovered that GST, but not MRP, accounts for the suppression of cisplatin entry to the nucleus by PRL. This action is mediated by the Jak-Stat and MAPK, but not PI3K, pathways. Subsequent studies show that PRL induces the expression of the GST mu isoform and increases GST enzyme activity in MDA-MB-468 cells [21]. The GST mu- and theta-null genotypes are associated with increased survival in women with advanced breast cancer treated with chemotherapy [22].
A model which conceptualizes the mechanism by which PRL confers resistance against cisplatin is presented in Fig. (1). After diffusing into the cell, cisplatin enters the nucleus and binds to DNA, with the ensuing cell cycle arrests leading to apoptosis. Binding of PRL to its receptor induces the activation of Jak-Stat and MAPK pathways, which separately or in concert, increase the expression and activity of GST. GST conjugates cisplatin to glutathione, leading to its extrusion from the cell. Consequently, less cisplatin is available for entering the nucleus and inflicting DNA damage. The overall effect of PRL is a marked reduction in cisplatin-induced cell death. In addition to cisplatin, GST confers resistance to doxorubicin but not to the microtubule altering drugs [23]. Thus, the mechanism by which PRL antagonizes drugs which are not substrates for GST may involve alterations in $\mathrm{Bcl}-2$ family proteins.

Recently, we used real-time PCR and discovered that several BCC express 30-40 fold more hGH and hPL than PRL (unpublished observations). Totally unexpected was the presence of hPL, believed to be produced only by the placenta during pregnancy. As evident by Western blotting, all three BCC examined express variable levels of the hPL protein, while immortalized, but non-malignant, epithelial breast cells had undetectable hPL. Similar to hPRL, hPL also confers chemoresistance against taxol and doxorubicin although the mechanism by which this occurs has not yet been examined. Whether $\mathrm{hGH}$ is also expressed at the protein level and confers resistance against chemotherapeutic agents is currently under investigation.

\section{INTERACTIONS BETWEEN PRL AND ESTROGENS}

An emerging concept in the development of chemoresistance is the contribution made by hormones. Unlike the major focus of research on estrogens as mitogens in breast cancer, only few studies have examined their role in chemoresistance. This oversight is enigmatic because stimulation of tumor growth by estrogens involves not only increased cell proliferation but also reduced cell death. Indeed, MCF-7 cells depleted of estrogen are twice as sensitive to doxorubicin than estrogen-treated cells, with estrogen depletion accompanied by decreased Bcl-2 expression while $\mathrm{Bcl}-2$ reconstitution restores resistance to doxorubicin [24]. Estrogen also reduced taxol cytotoxicity in cells overexpressing $\mathrm{ER} \alpha$, with the cells sensitized to taxol by treatment with the $\operatorname{ER} \alpha$ antagonist ICI [25]. Estrogen antagonizes taxol- and radiation-induced apoptosis by altering JNK activity [26].

A potential joint contribution by PRL and estrogens towards chemoresistance has not been extensively investigated. It is plausible that these hormones, working in concert, confer resistance against a variety of drugs [21]. PRL and estrogens are dissimilar in chemical structure, receptor characteristics and signaling mechanisms. Whereas estrogens can bind to several classical and non classical estrogen receptors, there is only one receptor for PRL, albeit it exists in several isoforms which couple to different signaling pathways [27]. Yet, there is a significant crosstalk between the two hormones, with PRL increasing the expression and phosphorylation of ER $\alpha$ [28], and E2 inducing transcription of both PRL [29], and the PRLR [27]. Notably, both hormones reach the breast from the systemic 


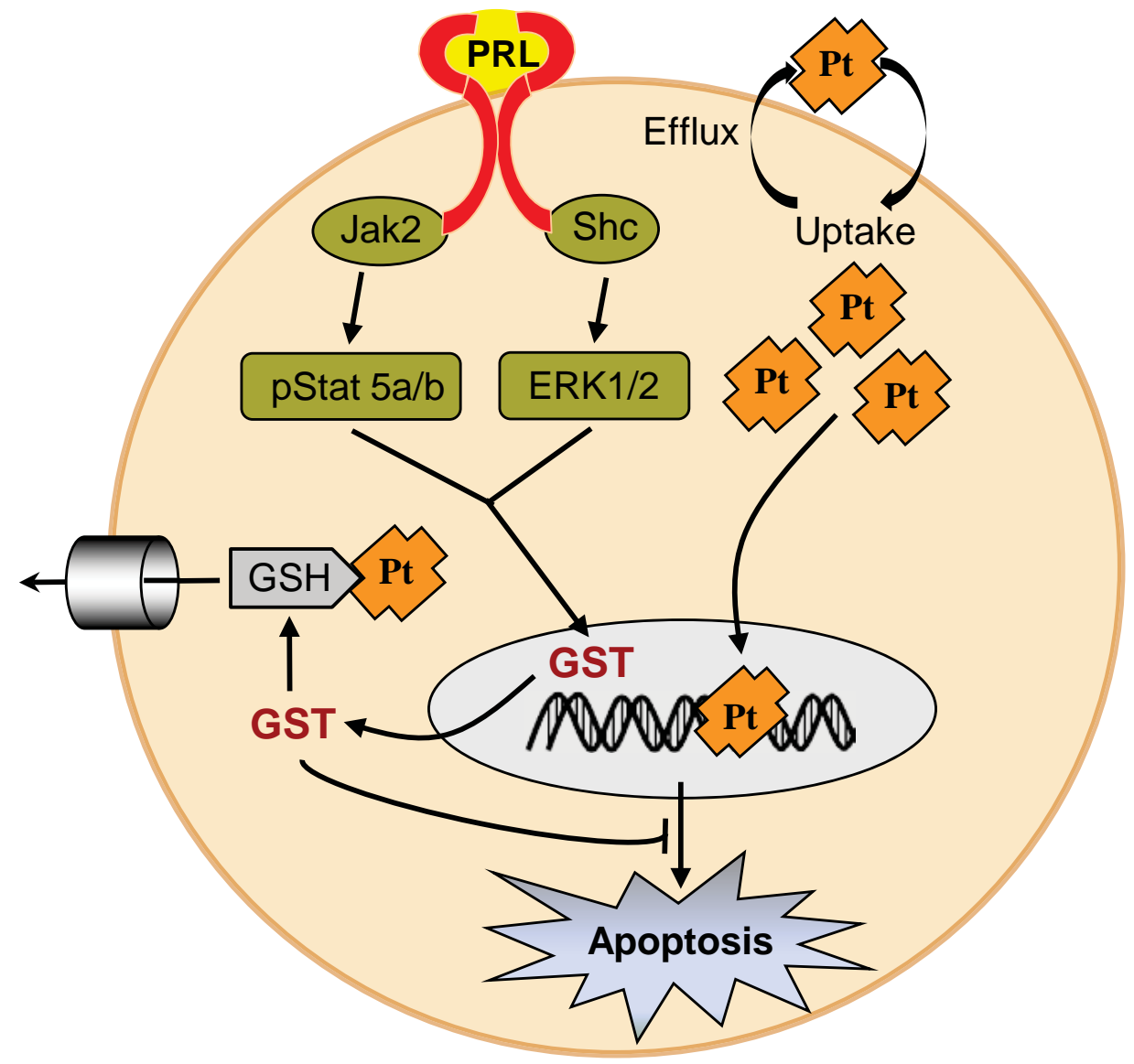

Fig. (1). Proposed mechanism by which PRL confers resistance against cisplatin in breast cancer cells. See text for further details.

circulation as well as from local sources, i.e., de novo synthesis of PRL by the breast, and conversion of androgens to estrogens by local aromatase [30]. Interactions between the two hormones can result in augmentation, or synergism, in the antagonism to anti-cancer drugs. Presumably, a strategy designed to dampen the PRL signal may find utility in ER-positive cancers, as the estrogen signaling pathway could be decreased as well.

\section{STRUCTURE AND SIGNALING OF THE PRLR}

The PRLR is a member of the class I cytokine receptor superfamily which are non-tyrosine kinase, single-pass membrane receptors [31]. The gene encoding the PRLR is located on chromosome 5, and is comprised of 10 exons spanning $100 \mathrm{~kb}$ [32]. The receptor has a tripartite organization, comprised of an extracellular ligand binding domain (LBD) which confers specificity, a short transmembrane domain, and an intracellular domain (ICD) which initiates signaling upon receptor occupancy. Alternative splicing generates at least nine variants of the human PRLR, which primarily differ in the lengths and composition of their cytoplasmic domains, and ultimately different signalling properties [27]. In addition to its cognate receptor, hGH also binds to the PRLR, and so does hPL, which does not have a distinct receptor of its own.

Receptor activation involves sequential binding to two distinct binding sites on the ligand, called site 1 and site 2 . Initially, one receptor binds to a high affinity site 1 , while a second receptor binds to a lower affinity site 2, thereby forming an active ternary complex composed of one hormone molecule and a receptor homodimer [33]. Recent studies, however, reported the existence of preformed, inactive dimers in the absence of ligand, suggesting that receptor dimerization is necessary but insufficient for its activation [34]. Nonetheless, the commonly accepted binding scheme consists of a single PRL molecule binding to two receptors. This ternary complex properly orients the ICD and associated Jak2 kinase into juxtaposition, enabling their activation by phosphorylation. Subsequently, Jak2 recruits several kinases, adaptor proteins and downstream signaling pathways which include Stat5a/b, MAPK and PI3K [7].

\section{THE PRLR AS A THERAPEUTIC TARGET}

Increasing evidence suggests that the PRLR is an excellent target in the treatment of breast cancer. For example, analysis of human breast tumors has shown that the majority of breast carcinomas express the PRLR, with neoplastic tissue expressing higher levels of the receptor than adjacent healthy tissue [35]. Blocking the PRLR, via a modified hPRL, G129RhPRL, introduced either as a transgene or as a fusion protein are useful as prophylactic tools in rodent models for mammary cancer [36].

Many potential sites along the PRL signaling pathways can be exploited in the pursuit of blocking PRL actions. These include ligand-receptor binding, receptor-receptor interactions, receptor-Jak2 binding, and Jak2 association 
with adaptor proteins. There are several reasons why the PRLR itself should be the prime target of molecular inhibition. First, the three lactogens, which are dissimilar in critical interacting residues, do not induce identical conformational changes in the receptor. Instead, each imposes a different stability on the active complex, thus affecting its dynamics and the binding parameters of the associated partners [37]. Hence, there are multiple outputs from the same receptor, all of which may have relevance to cancer biology. The best way to block this multifaceted output is to target the cascade at the most upstream event, the PRLR. Second, inhibiting PRL signaling at receptor level would prevent any cross talk interactions with other procancer pathways. Finally, simply targeting PRL production/release would be ineffective, due to the potential of activation of the signaling pathway by the other lactogens.

An emerging concept is interaction of PRL signaling with other pro-cancer signaling pathways. The best documented example are interactions between PRL and HER-2, a surface-bound receptor tyrosine kinase which is overexpressed in about $40 \%$ of breast carcinoma, and whose signaling leads to differention and mitogenesis [38]. HER-2 expression is associated with a shorter relapse time, metastasis, and a significantly decreased survival time for breast cancer patients. BCC overexpressing HER-2 proliferate faster are more able to metastasize in the presence of secreted PRL, with PRL induceing tyrosine phosphorylation of HER2, which is often constititively phosphorylated in breast cancer [39]. Notably, a simulatneous inhibition of the PRLR and HER-2 is more effective than inhibiting HER-2 alone in suppressing breast cancer cell proliferation [40].

\section{EXISTING PRLR ANTAGONISTS}

Underscoring the need to develop specific inhibitors of PRL signaling is the fact that treatment of breast cancer patients with the dopamine agonist bromocriptine, which blocks pituitary PRL release, did not have positive effects on tumor progression. Therefore, the development of molecules that can selectively block the PRL signaling pathway has been undertaken by several laboratories [41-43]. Several PRLR antagonists, made by point mutations in the PRL molecule, by a combination of deletion and mutations, or by fusions, have been developed. One approach involved a modified S179D hPRL intended to mimic phosphorylated PRL and act as an inhibitor. On the other hand, G129R hPRL was designed to disrupt receptor dimerization. Different deletions of the (e.g., $\Delta 1-9-G 129 R$ hPRL) were later developed so as to remove residual agonistic activity [41]. Finally, attempts were made to fuse the G129R hPRL to different proteins and create a bi-functional molecule that maintains the properties of both partners. Fusions partners included endostatin [44], to prevent angiogenesis, and Il-2 [45] with the hope that this cytokine would specifically mobilize the immune system against breast cancer cells. The G129R hPL was also fused to a bacterial toxin, with the intent of inhibiting both PRL signaling and protein synthesis [46].

Several of the mutated PRL molecules have shown a reasonable antagonistic activity in vitro and in experimental animals. However, the engineered PRL approach would not be efficacious for treating patients because of the necessity to deliver proteins by injections, their short half-life and the difficulty in achieving appropriate and sustained therapeutic levels. In addition to engineered PRL molecules, several antibody-based approaches for targeting the PRLR were developed. An earlier study reported that a monoclonal antibody against the PRLR reduced the frequency of both carcinomas and mammary hyperplasia in mice [47].

An antibody-based approach for patients would be hampered by finding a suitable antibody specific for the human version of the PRLR and the need to 'humanize' such antibodies to avoid immunological rejection. A list of PRL derived antagonists and their evaluation is presented in Table 1.

\section{SMALL MOLECULE INHIBITORS OF THE PRLR}

In light of the limitations of a protein based strategy together with ineffectiveness of extant treatments, the development of novel therapies targeted at the PRLR would certainly be warranted. An unexploited approach is the search for small molecule inhibitors which can be given orally. Typically, these molecules are discovered through the

Table 1. Approaches for Blocking PRL Signaling in Breast Cancer

\begin{tabular}{|c|c|c|}
\hline Molecular Approach & Advantage & Disadvantage \\
\hline $\begin{array}{c}\text { Bromocriptine and cabergoline (dopamine } \\
\text { agonists) }\end{array}$ & $\begin{array}{c}\text { FDA approved; very effective in suppressing } \\
\text { pituitary PRL release }\end{array}$ & $\begin{array}{l}\text { Not specific for the PRLR; does not prevent } \\
\text { action of other lactogens }\end{array}$ \\
\hline Modified versions of the PRL molecule & $\begin{array}{l}\text { Moderately successful under in vitro and in vivo } \\
\text { conditions in blocking the PRLR }\end{array}$ & $\begin{array}{l}\text { Requires iv delivery in patients; unclear how } \\
\text { they will be tolerated over time }\end{array}$ \\
\hline Antibodies against PRL and the PRLR & $\begin{array}{l}\text { Successes have been reported in vivo and in cell } \\
\text { cultures }\end{array}$ & $\begin{array}{l}\text { Requires iv delivery; must be humanized to } \\
\text { prevent immune responses }\end{array}$ \\
\hline $\begin{array}{c}\text { Combination of modified PRL with toxins or } \\
\text { angiogenic inhibitors }\end{array}$ & Some success with an in vivo system & $\begin{array}{c}\text { Complicated scheme; Likely impractical in } \\
\text { patients }\end{array}$ \\
\hline Cyclic peptides against the PRLR & $\begin{array}{c}\text { Stable; several drugs are based on cyclic peptides } \\
\text { or their derivatives }\end{array}$ & $\begin{array}{l}\text { Unproven; bind at } \mu \mathrm{M} \text { to the PRLR; antagonism } \\
\text { of the pathway not proven }\end{array}$ \\
\hline $\begin{array}{l}\text { Small molecules against the PRLR or its } \\
\text { signaling pathways }\end{array}$ & $\begin{array}{l}\text { Deliverable; amenable to modifications; many } \\
\text { drugs are from this class of compounds }\end{array}$ & $\begin{array}{l}\text { Small molecule inhibitors specific to the PRLR } \\
\text { are not yet available }\end{array}$ \\
\hline
\end{tabular}


use of high throughput screening (HTS) of 'libraries' of diverse chemical compounds.

HTS has been the mainstay of the pharmaceutical industry, resulting in many marketed drugs [48]. A case study at Bristol-Meyers Squib showed that HTS supplied the starting point for $65 \%$ of their new drug projects in 2008 [49]. In addition to identifying many effective compounds against $G$ protein-coupled receptors, several small molecule inhibitors of nuclear and cytokine receptors have been discovered using HTS [50-52]. A combination of computerbased modeling and virtual screening, rationale selection of drug-like compounds of different structures, and sensitive and reliable cell-based readouts, are mandatory for HTS success [53] (Fig. (2)).

HTS has been the mainstay of the pharmaceutical industry, resulting in many marketed drugs [48]. A case study at Bristol-Meyers Squib showed that HTS supplied the starting point for $65 \%$ of their new drug projects in 2008 [49]. In addition to identifying many effective compounds against $G$ protein-coupled receptors, several small molecule inhibitors of nuclear and cytokine receptors have been discovered using HTS [50-52]. A combination of computerbased modeling and virtual screening, rationale presents a flow diagram for conducting HTS for small molecule inhibitors of PRL. Based on the precedent of screens of small molecule agonsists/ antagonists of other receptors, a yield of $\sim 1$ validated hit for every 1000 molecules screened is expected. Although early 'hits' may bind only at $\mu \mathrm{M}$ concentrations, they should serve as seeds for subsequent modifications by medicinal chemistry.

To date there is a lone report that has searched for small molecules that bind to the PRLR [54]. A library of small cyclic peptides was synthesized on a solid support and was screened for activity to bind the extracellular domain of the PRLR which was fluorescently labeled. From a $1.2 \times 10^{7}$ member library, 20 'hits' were discovered, with binding constants in 2-3 $\mu \mathrm{M}$ range. However, the authors did not report how well this class of molecules worked on living cells, or whether such molecules had any competitive antagonistic activity. In theory, cyclic peptides are more resistant to proteolysis and should be able to specifically bind to receptors. Indeed, cyclic peptides such as cyclosporine A, daptomycin, and caspofungin have found many therapeutic uses.

\section{THE DESIGN OF SMALL MOLECULE LIBRARY}

The design of a small molecule library is often based on the 'Lipinski's rules of 5' [55], which is geared to maximize the chances that the compound would be orally active in humans. There are two broad means by which the library can be created. One consists of parallel synthesis where combinatorial chemistry is employed to make a library consisting of a superfamily of molecules [56]. The advantages of this approach is that a very large library could be rapidly generated, and identified hits could be amenable to subsequent chemical modification aimed at refining their properties. The limitations of this approach is that the library does not sample the total 'chemical space'. Alternatively, a library can be generated by having a diverse array of small molecules that have no individual relationship or common theme, yet the whole library occupies a vast chemical space. A diversity oriented library maximizes chirality and molecular rigidity, two factors that are of great importance in the design of pharmaceuticals. The problem with a diversity oriented library is the difficulty, from a medicinal chemistry stand point, to hone in on a given small molecule of interest.

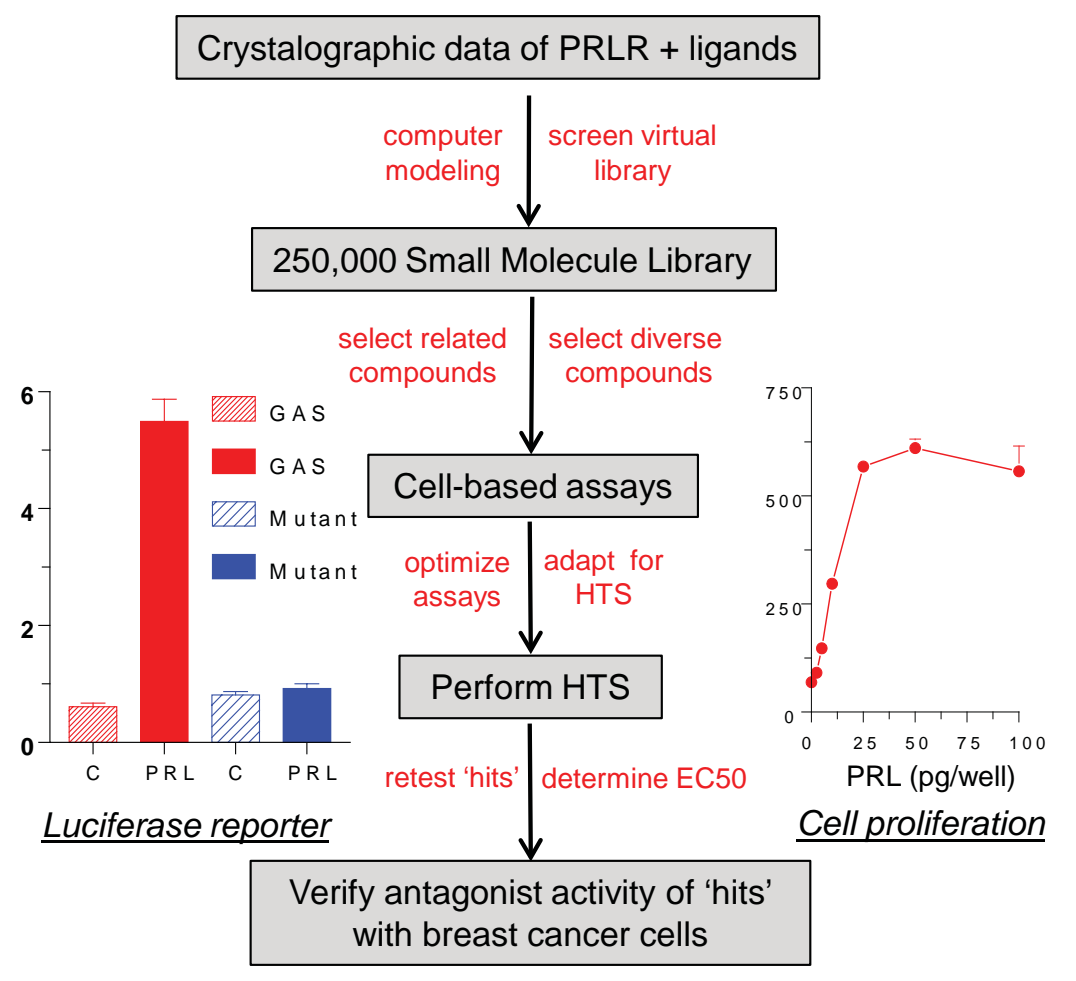

Fig. (2). Flow diagram for identifying small molecule inhibitors of the PRLR. 


\section{PERSPECTIVES AND VISIONS OF THE FUTURE}

An important facet in the advancement of breast cancer therapies will be through the identification and development of novel small molecules that selectively inhibit this receptor. Future treatment of breast cancer patients could witness the use of such inhibitors in tandem with existing treatment modules in order to both inhibit tumor growth and to make it more amenable to the cytotoxic effects of chemotherapeutic agents. The genotype of a patient's PRLR may well dictate how and which antagonists are best employed.

\section{ACKNOWLEDGEMENTS}

This work was supported by NIH grants ES012212 and CA096613, Department of Defense grant BC05725 and Susan G. Komen Breast Cancer Foundation grant BCRT87406 (to NBJ).

\section{ABBREVIATIONS}

$\mathrm{BCC}=$ Breast Cancer Cells
$\mathrm{ER}=$ Estrogen Receptor
$\mathrm{GST}=$ Glutathione-S-Transferase
$\mathrm{hGH}=$ Human Growth Hormone
$\mathrm{hPL}=$ Human Placental Lactogen
$\mathrm{HTS}=$ High Throughput Screening
$\mathrm{ICD}=$ Intracellular Domain
$\mathrm{LBD}=$ Ligand Binding Domain
$\mathrm{MRP}=$ Multi-drug Resistant Proteins
$\mathrm{PR}=$ Progesterone Receptor
$\mathrm{PRL}=$ Prolactin
PRLR $=$ Prolactin Receptor
SERM $=$ Selective Estrogen Receptor Modulators
REFERENCES

[1] Coley, H.M. Mechanisms and strategies to overcome chemotherapy resistance in metastatic breast cancer. Cancer Treat. Rev., 2008, 34, 378-90.

[2] Lewis, J.S.; Jordan, V.C. Selective estrogen receptor modulators (SERMs): mechanisms of anticarcinogenesis and drug resistance. Mutat. Res., 2005, 591, 247-63.

[3] Kesisis, G.; Makris, A.; Miles, D. Update on the use of aromatase inhibitors in early-stage breast cancer. Breast Cancer Res., 2009, 11,211-7.

[4] Slamon, D.; Pegram, M. Rationale for trastuzumab (Herceptin) in adjuvant breast cancer trials. Semin. Oncol., 2001, 28, 13-9.

[5] Knoop, A.S.; Knudsen, H.; Balslev, E.; Rasmussen, B.B.; Overgaard, J.; Nielsen, K.V.; Schonau, A.; Gunnarsdottir, K.; Olsen, K.E.; Mouridsen, H.; Ejlertsen, B.; Danish Breast Cancer Cooperative Group. Retrospective analysis of topoisomerase IIa amplifications and deletions as predictive markers in primary breast cancer patients randomly assigned to cyclophosphamide, methotrexate, and fluorouracil or cyclophosphamide, epirubicin, and fluorouracil. J. Clin. Oncol., 2005, 23, 7483-90.

[6] Davis, J.C.; Furstenthal, L.; Desai, A.A.; Norris, T.; Sutaria. S.; Fleming, E.; Ma, P. The microeconomics of personalized medicine: today's challenge and tomorrow's promise. Nat. Rev. Drug Discov., 2009, 8, 279-86.

[7] Clevenger, C.V.; Furth, P.A.; Hankinson, S.E.; Schuler, L.A. The role of prolactin in mammary carcinoma. Endocr. Rev., 2003, 24, $1-27$.
[8] Ben-Jonathan, N.; Mershon, J.L.; Allen, D.L.; Steinmetz, R.W. Extrapituitary prolactin: distribution, regulation, functions, and clinical aspects. Endocr. Rev., 1996, 17, 639-69.

[9] Soares, M.J. The prolactin and growth hormone families: pregnancy-specific hormones/cytokines at the maternal-fetal interface. Reprod. Biol. Endocrinol., 2004, 2, 51-66.

[10] Teilum, K.; Hoch, J.C.; Goffin, V.; Kinet, S.; Martial, J.A.; Kragelund, B.B. Solution structure of human prolactin. J. Mol. Biol., 2005, 351, 810-23.

[11] Ben-Jonathan, N.; Lapensee, C.R.; Lapensee, E.W. What can we learn from rodents about prolactin in humans? Endocr. Rev., 2008, $29,1-41$.

[12] Tworoger, S.S.; Hankinson, S.E. Prolactin and breast cancer etiology: an epidemiologic perspective. J. Mammary Gland Biol. Neoplasia, 2008, 13, 41-53.

[13] Clevenger, C.V.; Gadd, S.L.; Zheng, J. New mechanisms for PRLr action in breast cancer. Trends Endocrinol. Metab., 2009, 20, 2239.

[14] Liby, K.; Neltner, B.; Mohamet, L.; Menchen, L.; Ben-Jonathan, N. Prolactin overexpression by MDA-MB-435 human breast cancer cells accelerates tumor growth. Breast Cancer Res. Treat., 2003, 79, 241-52.

[15] Zinger, M.; McFarland, M.; Ben-Jonathan, N. Prolactin expression and secretion by human breast glandular and adipose tissue explants. J. Clin. Endocrinol. Metab., 2003, 88, 689-96.

[16] Reynolds, C.; Montone, K.T.; Powell, C.M.; Tomaszewski, J.E.; Clevenger, C.V. Expression of prolactin and its receptor in human breast carcinoma. Endocrinology, 1997, 138, 5555-60.

[17] Rose-Hellekant, T.A.; Arendt, L.M.; Schroeder, M.D.; Gilchrist, K.; Sandgren, E.P.; Schuler, L.A. Prolactin induces ERalphapositive and ERalpha-negative mammary cancer in transgenic mice. Oncogene, 2003, 22, 4664-74.

[18] Welsch, C.W.; Nagasawa, H. Prolactin and murine mammary tumorigenesis: a review. Cancer Res., 1977, 37, 951-63.

[19] Lapensee, E.W.; Schwemberger, S.J.; Lapensee, C.R.; Bahassi, eM,; Afton, S.E.; Ben-Jonathan, N. Prolactin confers resistance against cisplatin in breast cancer cells by activating glutathione-Stransferase. Carcinogenesis, 2009, 30, 1298-304.

[20] Siddik, Z.H. Cisplatin: mode of cytotoxic action and molecular basis of resistance. Oncogene, 2003, 22, 7265-79.

[21] Lapensee, E.W.; Fox, S.; Schwemberger, S.J.; Afton, S.; BenJonathan, N. Bisphenol A and Estradiol are equipotent in antagonizing cisplatin cytotoxicity in breast cancer cells. Endocr. Relat. Cancer, 2009, in press.

[22] Ambrosone, C.B.; Sweeney. C.; Coles, B.F.; Thompson, P.A.; McClure, G.Y.; Korourian, S.; Fares, M.Y.; Stone, A.; Kadlubar, F.F.; Hutchins, L.F. Polymorphisms in glutathione S-transferases (GSTM1 and GSTT1) and survival after treatment for breast cancer. Cancer Res., 2001, 61, 7130-5.

[23] L'Ecuyer, T.; Allebban, Z.; Thomas, R.; Vander, H.R. Glutathione S-transferase overexpression protects against anthracycline-induced H9C2 cell death. Am. J. Physiol. Heart Circ. Physiol., 2004, 286, H2057-H2064.

[24] Teixeira, C.; Reed, J.C.; Pratt, M.A. Estrogen promotes chemotherapeutic drug resistance by a mechanism involving $\mathrm{Bcl}-2$ proto-oncogene expression in human breast cancer cells. Cancer Res., 1995, 55, 3902-7.

[25] Sui, M.; Huang, Y.; Park, B.H.; Davidson, N.E.; Fan, W. Estrogen receptor alpha mediates breast cancer cell resistance to paclitaxel through inhibition of apoptotic cell death. Cancer Res., 2007, 67, 5337-44.

[26] Razandi, M.; Pedram, A.; Levin, ER. Plasma membrane estrogen receptors signal to antiapoptosis in breast cancer. Mol. Endocrinol., 2000, 14, 1434-47.

[27] Swaminathan, G.; Varghese, B.; Fuchs, S.Y. Regulation of prolactin receptor levels and activity in breast cancer. J. Mammary Gland Biol. Neoplasia, 2008, 13, 81-91.

[28] Carver, K.C.; Arendt. L.M.; Schuler, L.A. Complex prolactin crosstalk in breast cancer: new therapeutic implications. Mol. Cell Endocrinol., 2009, 307, 1-7.

[29] Duan, R.; Ginsburg, E.; Vonderhaar, B.K. Estrogen stimulates transcription from the human prolactin distal promoter through AP1 and estrogen responsive elements in T47D human breast cancer cells. Mol. Cell Endocrinol., 2008, 281, 9-18.

[30] Foster, P.A. Steroid metabolism in breast cancer. Minerv. Endocrinol., 2008, 33, 27-37. 
[31] Bole-Feysot, C.; Goffin, V.; Edery, M.; Binart, N.; Kelly, P.A. Prolactin (PRL) and its receptor: actions, signal transduction pathways and phenotypes observed in PRL receptor knockout mice. Endocr. Rev., 1998, 19, 225-68.

[32] Hu, Z.Z.; Zhuang, L.; Dufau, M.L. Prolactin receptor gene diversity: structure and regulation. Trends. Endocrinol. Metab., 1998, 9, 94-102.

[33] Svensson, L.A.; Bondensgaard, K.; Norskov-Lauritsen, L.; Christensen, L.; Becker, P.; Andersen, M.D.; Maltesen, M.J.; Rand, K.D.; Breinholt, J. Crystal structure of a prolactin receptor antagonist bound to the extracellular domain of the prolactin receptor. J. Biol. Chem., 2008, 283, 19085-94.

[34] Gadd, S.L.; Clevenger, C.V. Ligand-independent dimerization of the human prolactin receptor isoforms: functional implications. Mol. Endocrinol., 2006, 20, 2734-46.

[35] Touraine, P.; Martini, J.F.; Zafrani, B.; Durand, J.C.; Labaille, F.; Malet, C.; Nicolas, A.; Trivin, C.; Postel-Vinay, M.C. Kuttenn, F.; Kelly, P.A. Increased expression of prolactin receptor gene assessed by quantitative polymerase chain reaction in human breast tumors versus normal breast tissues. J. Clin. Endocrinol. Metab., 1998, 83, 667-74.

[36] Tomblyn, S.; Springs, A.E.; Langenheim, J.F.; Chen, W.Y. Combination therapy using three novel prolactin receptor antagonist-based fusion proteins effectively inhibits tumor recurrence and metastasis in HER2/neu transgenic mice. Int. J. Oncol., 2009, 34, 1139-46.

[37] Gertler, A.; Grosclaude, J.; Strasburger, C.J.; Nir, S.; Djiane, J. Real-time kinetic measurements of the interactions between lactogenic hormones and prolactin-receptor extracellular domains from several species support the model of hormone-induced transient receptor dimerization. J. Biol. Chem., 1996, 271, 2448291.

[38] Paik, S.; Hazan, R.; Fisher, E.R.; Sass, R.E.; Fisher, B.; Redmond, C.; Schlessinger, J.; Lippman, M.E.; King, C.R. Pathologic findings from the National Surgical Adjuvant Breast and Bowel Project: prognostic significance of erbB-2 protein overexpression in primary breast cancer. J. Clin. Oncol., 1990, 8, 103-12.

[39] Yamauchi, T.; Yamauchim, N.; Ueki, K.; Sugiyama, T.; Waki, H.; Miki, H.; Tobe, K.; Matsuda, S.; Tsushima, T.; Yamamoto, T.; Fujita, T.; Taketani, Y.; Fukayama, M.; Kimura, S.; Yazaki, Y.; Nagai, R.; Kadowaki, T. Constitutive tyrosine phosphorylation of ErbB-2 via Jak2 by autocrine secretion of prolactin in human breast cancer. J. Biol. Chem., 2000, 275, 33937-44.

[40] Fuh, G.; Wells, J.A. Prolactin receptor antagonists that inhibit the growth of breast cancer cell lines. J. Biol. Chem., 1995, 270, 13133-7.

[41] Goffin, V.; Bernichtein, S.; Touraine, P.; Kelly, P.A. Development and potential clinical uses of human prolactin receptor antagonists. Endocr. Rev., 2005, 26, 400-22.

[42] Chen, N.Y.; Holle, L.; Li, W.; Peirce, S.K.; Beck, M.T.; Chen, W.Y. In vivo studies of the anti-tumor effects of a human prolactin antagonist, hPRL-G129R. Int. J. Oncol., 2002, 20, 813-8.
[43] Walker, A.M. Prolactin receptor antagonists. Curr. Opin. Investig., Drugs, 2005, 6, 378-385.

[44] Beck,M.T., Chen, N.Y.; Franek, K.J.; Chen, W.Y. Prolactin antagonist-endostatin fusion protein as a targeted dual-functional therapeutic agent for breast cancer. Cancer Res., 2003, 63, 3598604.

[45] Zhang, G.; Li, W.; Holle, L.; Chen, N.; Chen, W.Y. A novel design of targeted endocrine and cytokine therapy for breast cancer. Clin. Cancer Res., 2002, 8, 1196-205.

[46] Langenheim, J.F.; Chen, W.Y. Development of a prolactin receptor-targeting fusion toxin using a prolactin antagonist and a recombinant form of Pseudomonas exotoxin A. Breast Cancer Res. Treat., 2005, 90, 281-93.

[47] Sissom, J.F.; Eigenbrodt, M.L.; Porter, J.C. Anti-growth action on mouse mammary and prostate glands of a monoclonal antibody to prolactin receptor. Am. J. Pathol., 1988, 133, 589-95.

[48] Fox, S.; Farr-Jones, S.; Sopchak, L.; Boggs, A.; Nicely, H.W.; Khoury, R.; Biros, M. High-throughput screening: update on practices and success. J. Biomol. Screen., 2006, 11, 864-9.

[49] Houston, J.G.; Banks, M.N.; Binnie, A.; Brenner, S.; O'Connell, J.; Petrillo, E.W. Case study: impact of technology investment on lead discovery at Bristol-Myers Squibb, 1998-2006. Drug Discov. Today, 2008, 13, 44-51.

[50] Busch-Petersen, J. Small molecule antagonists of the CXCR2 and CXCR1 chemokine receptors as therapeutic agents for the treatment of inflammatory diseases. Curr. Top. Med. Chem., 2006, $6,1345-52$

[51] Shao, D.; Berrodin, T.J.; Manas, E.; Hauze, D.; Powers, R.; Bapat, A.; Gonder. D.; Winneker, R.C.; Frail, D.E. Identification of novel estrogen receptor alpha antagonists. J. Steroid Biochem. Mol. Biol., 2004, 88, 351-60.

[52] Arkin, M.R.; Randal, M.; DeLano, W.L.; Hyde, J.; Luong, T.N.; Oslob, J.D.; Raphael, D.R.; Taylor, L.; Wang, J.; McDowell, R.S.; Wells, J.A.; Braisted, A.C. Binding of small molecules to an adaptive protein-protein interface. Proc. Natl. Acad. Sci. USA, 2003, 100, 1603-8.

[53] Lazo, J.S.; Brady, L.S.; Dingledine, R. Building a pharmacological lexicon: small molecule discovery in academia. Mol. Pharmacol. 2007, 72, 1-7.

[54] Liu, T.; Joo, S.H.; Voorhees, J.L.; Brooks, C.L.; Pei, D. Synthesis and screening of a cyclic peptide library: discovery of smallmolecule ligands against human prolactin receptor. Bioorg. Med. Chem., 2009, 17, 1026-33.

[55] Lipinski, C.A.; Lombardo, F.; Dominy, B.W.; Feeney, P.J. Experimental and computational approaches to estimate solubility and permeability in drug discovery and development settings. $A d v$. Drug Deliv. Rev., 2001, 46, 3-26.

[56] Shuttleworth, S.J.; Connors, R.V.; Fu, J.; Liu, J.; Lizarzaburu, M.E.; Qiu, W.; Sharma, R.; Wanska, M.; Zhang, A.J. Design and synthesis of protein superfamily-targeted chemical libraries for lead identification and optimization. Curr. Med. Chem., 2005, 12, 123981 .

(C) Jacobson et al.; Licensee Bentham Open.

This is an open access article licensed under the terms of the Creative Commons Attribution Non-Commercial License (http://creativecommons.org/licenses/by-nc/3.0/) which permits unrestricted, non-commercial use, distribution and reproduction in any medium, provided the work is properly cited. 